\title{
El Proceso Penal en sus relaciones con el Proceso Civil
}

\author{
Por el Doctor DOMINGo GARCIA RADA \\ Juez Instructor de Lima, \\ Catedrático de la Universidad Católica
}

\begin{abstract}
Con el propósito de ofrecer una visión de conjunto de ambos procesos para destacar sus diferencias y semejanzas, trazaremos a continuación los rasgos principales de cada uno, sin pretender agotar la materia. La comparación será tanto del punto de vista doctrinario, como del articulado.
\end{abstract}

Al tratar del Mandar Jurídico en su Teoría General del Derecho, el Profesor Carnelutti hace hincapie en que, en toda relación social, hay un interés de por medio entre las partes y la cosa; siempre vendedor y comprador, donante y donatario, agresor y víctima están divididos por un interés contrario respecto a una misma cosa. El interés es la utilidad que ofrece determinada cosa a una persona, la cual se siente atraída hacia ella impulsada por una necesidad presente o futura, material o espiritual.

Ante los bienes del universo, el hombre puede encontrarse en dos situaciones: de atracción o de indiferencia. La posición de atracción puede ser de solidaridad o de conflicto, según pueda satisfacerla de modo pacífico o encuentre oposición, es decir que el interés de la otra persona no se avenga con el suyo. La causa de los intereses en conflicto radica--según lo anota este eminente profesor Italiano -en la "limitación de los bienes". Cuando dos hombres extraños el uno al otro, pretenden la misma cosa se: produce un conflicto de alcances desconocidos y que pueden llegar hasta la violencia. La existencia de la sociedad impone la solución pacífica de los conflictos. Para garantizar la justa solución de las controversias y así alcanzar la paz social, interviene el Derecho que es quien la logra mediante la justicia. Sin justicia no puede darse una auténtica paz social.

Tal es la función del Derecho. Regular en justicia todos los con. flictos de intereses que puedan presentarse. Es buen sintoma en una sociedad, la disminución de las controversias judiciales, y que cuando llegan a presentarse se solucionen conforme a la razón. Cuanto mayor predominio 
Enga a ética, será menos necesaria la función reguiadora del derecho. Por evo Conchiti ha dicho acertadamente. "a medida que la norma tima va atginendo faema el derecho pierde poco a poco su razón de ser.... La Watida pesar de perderse sus origenes en el tiempo, se hal a to.

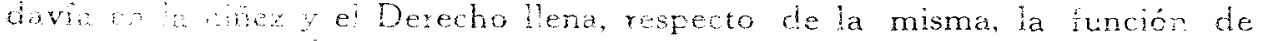
un aprato otopedico. Despues de lo manifestado espero no ser mal complancico en un libro reciente he osado sristiruir la superctición del ada vez más cecho por la verdad del cada vez menos derecho". (Teoría Genera! del Derecho, pág. 57).

En torio conficto de intereses hay dos sujctos y un objeto. Siempre existe ano gue desea algo -material o inmaterial-y otro que se opone a sativace ese deseo. los sujetos pueden ser varios, pero representarán una situacion de pedido o de oposición. Se denominan "partes". "Le parte no es solo el sujeto en sí, sino el sujeto en su posición en la relación". Ei conflicto supone un acto realizado por cada uno de 'os sujetos quienes así se: convierten en dos contendores, uno "pretende" y el otro se "opone a la pretensión". La pretensión - según Carneluti_- viene a ser la exigencia de le preponderancia de un irterés propio ante un interés ajeno"; la opo sición es contraria a esta pretensión. El litigio puede surgir tanto cuando se afectan a intereses de orden privado. que cuando se afectan a inlereses de orden colectivo, es decir bien sea el choque entre in dividuos o entre el individuo y la colectividad, resultando agraviado uno de sus miembros.

Este conflicto de intereses en marcha es lo que se denomina litigio. Para regularlo las scciedades organizadas, mejor dicho los Estados, dictan normas de derecho que son de orden público, a las cuales deben someterse forzosamente quienes litigan.

En el ejercicio de su función jurisdiccional, el Estado dicta preceptos que tienen por objeto resolver las alteraciones a la ley que pueden presentarse. Con este objeto crea los órganos, fijando sus atribuciones y estableciendo límites en su actuación. "La función judicial -dice el Profesor Alsina- es un poder, pero también es un deber y la ley debe determinar los casos y las condiciones en que puede exigirse su ejercicio (Tratado de Derecho Procesal Civil. I. pág. 33). Juntamente con la determinación de la función judicial, que se refiere a los jueces, se establece la forma como deben actuar las partes en los estrados judiciales. Para lograr esta finalidad esencial, el Estado organiza el procedimiento al cual se sumeterán las partes y. el juez en el curso de la tramitación hasta la sentencia que resolverá de manera definitiva e inmutable la controversia, mediante el apoyo que prestará el propio Estado para ejecutar la resolución final, único medio de lograr que el resultado no sea ilusorio y vano.

El carácter de la norma procesal es de derecho público. Varios pro. cesalistas distinguidos, entre ellos J. Ramiro Podetti en su interesantísimo libro "Teoría y Técnica del Proceso Civil", consideran que por participar el derecho procesal "de los caracteres del derecho público y del derecho privado no se le puede englobar en ninguna de las dos categorias" (pág. 56). A pesar de ser exacta esta afirmación, consideramos que en el derecho procesal predominan las normas del público sobre las del privado; por otra parte no existe el derecho público puro ni el privado puro, por lo cual en la calificación debe atenderse al carácter sobresaliente. 
En el procedimiento predomina el concepto de que es al Estado a quien se le pide amparo, y es el Juez, que personifica al Estado, quien dicta las providencias para amparar en su derecho al demandante. El titular de un derecho violado con su demanda pone en movimiento a todo el engranaje judicial, que constituye un poder del Estado, hasta lograr una resolución final, la que se lleva a efecto con el apoyo del mismo Estado. Si la actuación del poder público en el proceso civil, es preponderante, en el penal es decisivo y por su cuenta hace toda la instrucción. Por estas y muchas más consideraciones, se estima que la norma procesal pertenece al derecho pú. blico, a pesar de que contenga normas de derecho privado, pero estas en mucho menos proporción que no dan la tónica al proceso.

\section{EL PROCESO CIVIL}

El procedimiento no es otra cosa - dice Alsina- que el conjunto de formalidades a que deben someterse el juez y las partes en la tramitación del proceso. Etimológicamente indica la idea de marcha a seguir (procedere, avanzar) ; implica una serie de actos que en conjunto constituyen la instancia o proceso, durante los cuales el actor formula sus pretensiones, el demandado opone su defensa, ambos ofrecen sus pruebas y concluye todo con la sentencia que dicta el juez.

Cuando el litigio versa sobre aspectos propios del derecho privado, existen normas reguladoras que están contenidas en el Código de Procedimientos Civiles; sus preceptos establecen de qué manera se aplicará la ley en el caso controvertido.

El proceso civil es el seguido en la sustanciación de asuntos de derecho privado. Una persona se presenta ante los Tribunales pidiendo ser amparada jurídicamente frente a otra, en demanda de un derecho violado. Es el camino concebido para la aplicación del derecho. En el proceso civil se examina un derecho (la pretensión del actor) y segun su resultado será la sentencia que se obtenga. Es diverso el papel de las partes y del juez; las partes empiezan invocando la autoridad estatal, luego formulan sus alegaciones aportando las pruebas y concluyen presentando alegatos como resumen de su posición en la relación procesal; por su parte el juez escucha la pretensión, recibe y aprecia la prueba y dicta la sentencia que viene a ser la ley aplicada al caso debatido y cuyo fiel cumplimiento obliga a los contendores.

Todo individuo miembro de la colectividad, tiene la facultad de provocar la acción del Poder Judicial, cuando su derecho, debidamente amparado, ha sido violado o menospreciado. Esta facultad constituye la Acción. Ella importa la afirmación de una pretensión, pero quien la provoca está obligado a probar y demostrar su mejor derecho. El Juez, que personificará fisicamente al Poder Judicial, recibirá el llamado y las pruebas, las apreciará según reglas prefijadas, y determinando la norma aplicable al caso controvertido, resolverá en justicia la pretensión.

La "Acción es un derecho público subjetivo dirigido contra el Es- 
tado para obtener la tutela jurídica del mismo mediante sentencia favorable", según admirable definición del maestro James Goldschmidt en su Derecho Procesal Civil. El derecho a la acción es un derecho contra el Estado, pero cuya carga recae sobre quien lo provoca, o sea sobre el demandado.

Los presupuestos de la acción procesal, o requisitos de la tutela jurídica, son las siguientes, según el mismo maestro germano:

a) un determinado estado de hecho corespondiente a una pretensión de derecho privado, v.g. la autenticidad de un documento.

b) tal estado de hecho debe ser susceptible de protección jurídica, es decir debe estar amparado por la ley de manera expresa e inequívoca;

c) debe haber una verdadera necesidad de interés o tutela judicial; el actor debe tener un interés inmediato y auténtico.

Para el estudio general del desenvolvimiento de! proceso civil, seguiremos el método que emplea el Profesor Couture en sus "Fundamentos del Derecho Procesal Civil", dividiendo el tema en las siguientes partes.

1.-Constitución del Proceso.- El acto inicial de la relación procesal es la demanda, pues el proceso civil funciona a iniciativa de parte. La acción funciona desde la demanda hasta la sentencia; vive y actúa con prescindencia del derecho sustancial que quiere ver protegido.

La demanda resume las pretensiones del actor y es la que abre el proceso. Tiene enorme importancia por que es la base del juicio y de ella depende el éxito de la acción; concreta las pretenciones del actor y limita los poderes del juez, puesto que en su sentencia ilene que limitarse a las pretensiones expuestas en este primer documento.

Los efectos procesales de la demanda pueden resumirse así:

a) abre la instancia, obligando al Juez a considerar las peticiones del actor $y$ a éste a seguir el juicio bajo pena de perder sus derechos;

b) fija la competencia del juez con relación al actor;

c) obliga a! juez a conocer del juicio juzgándólo en su oportunidad;

d) fija la extensión del litigio y los poderes del Juez, quien sentenciará según lo pedido en la demanda;

e) origina el estado de litis-pendencia, que a su vez puede servir de base a una excepción de pleito pendiente si hay demanda posterior sobre el mismo asunto;

f) con respecto al derecho reclamado, impide la prescripción; y

g) en caso de ser declarada fundada, retrotrae sus efectos al día de la citación.

Requiere formalidades para ser admitida, y de no reunirlas puede ser rechazada de plano. La primera será la designación del funcionario judicial sin expresión persona! alguna; requerirá individualizar al demandante y demandado par ver si tienen capacidad para litigar y si son ellas, indicando el domicilio, el que fija la competencia del juez; deberá determinar con precisión el objeto de la petición; y firalmente indicará los fundamentos de hecho y de derecho en que se apoya. Estos requisitos son importantísimos no solo para su admisión, siro también para el desarrollo ulterior del proceso.

La respuesta a la demanda, será la Contestación que tendrá para 
el demandado la misma importancia que la demanda para el actor. Contestada la demanda queda establecida la relación procesal y firme el escrito de demanda que ya no puede ser alterado sustancialmente. La demanda y su contestación delimitan el proceso; fijan los límites del juicio del cual ya no pueden salirse las partes. Sus requisitos son iguales a los de la demanda.

Al ser notificado con una demanda, el demandado puede tomar varios caminos:

1) Conviene en la acción, allanándose a la demanda, con lo cual termina el juicio:

2) Contradice la acción; si hay hechos que probar, se recibe la causa a prueba y se tramita hasta la sentencia final;

3) No constesta la demanda, sino que entabla excepciones que pueden tener por objeto dilatar la constestación, o matar la acción;

4) Constesta la demanda, entablando reconvención, en cuyo caso sigue la tramitación corriente del juicio.

La Excepción "es un medio legal de destruir o aplazar la acción intentada". Es un derecho de impugnación a la demanda y sus limites están señalados por ésta. Demanda y Excepción tienen iguales limites, pero orientados en sentido inverso. La excepción solo ataca la acción propuesta, dejando indemnes las que en el futuro se intenten.

Pueden ser de dos clases: dilatorias y perentorias. Las primeras tienden a dilatar o postergar la contestación de la demanda: son netamente procesales, versan sobre el proceso, no sobre la acción. Tienen por objeto eliminar ciertas cuestiones que podrían obstaculizar el fin del proceso; economizan fuerzas inútiles, evitando seguir juicios con defectos graves que pueden acarrear la nulidad de todo lo actuado. En cambio las perentorias versan sobre el derecho mismo, no sobre el proceso; es una defensa de fondo sobre el derecho cuestionado. Mientras las primeras suspenden el proceso, estas segundas - o sean las perentorias- conviven con el proceso y se resuelven conjuntamente, pero de declararse fundadas ya no se resuelve sobre lo demás porque sería inútil, puesto que la excepción ha resuelto el punto controvertido. Las dilatorias están texativamente señaladas en el código, no así las perentorias. Delimitado el campo en que se va a desarrollar el proceso, pasamos a la segunda etapa, o sea al:

11. Desarrollo del Proceso.- Establecicla legalmente la materia cuestionada, viene el periodo probatorio siempre que existan hechos que probar, no siendo necesario en el caso de ser la causa de puro derecho. En la prueba se trata de crear convicción en el magistrado mediante los hechos. que se alegan como fundamento del derecho.

Probar es demostrar la verdad de una proposición; es la confrontación de la versión de cada parte con los medios producidos para abonarla.

Objeto de la prueba son los hechos ofrecidos como fundamento del derecho del actor, puesto que el derecho no se prueba, salvo raras excepciones ( $v$. g. derecho extranjero aplicable al caso). No todos los hechos requieren prueba; sólo exigen probanda los controvertidos, pues los aceptados por las partes no requieren ser probados. Tampoco puede admitirse prueba sobre hechos no articulados en la demanda o en la contestación, pues ello modificaría el litigio. Igualmente no cabe probar hechos 
presumidos por la ley, pues por tal circunstancia han sido eliminados del campo de cualquier debate. Los hechos evidentes y los notorios no requieren ser probados por formar parte del acervo común de los hombres - jueces y litigantes- y sería inútil y perjudicial para la rapidez de la justicia, e dceplar prueba sobre ellos. Todos los demás hechos exigen prueba, semre gue reúnan dos requisitos: pertinencia y acmisibilidad, o sea en otra pabras que veisen sobre lo controvertido, y que sirvan para acreditar la verosmilided de lo afirmado.

En crinto a la carga de la prueba, existe el concepto latino "actio incumbit probatio"; el demandado puede limitarse a espertar el resuliedo de la prueba del actor, o a su vez puede strecer una contra prue. ba. Un procesalista contemporáneo dice al respecto: "Es de cargo de quien To alegue la prubba de la existencia del hecho en que se funde el derecho cuyo reconocimiento se pretende o que impida su constitución, modificación o extinga un derecho existente". Ya no puede aceptarse de manera exclusiva la regla latina, pues existen casos en que sería insuficiente. El Profesor Alsina consigna las reglas siguientes: 1) al actor incumbe la prueba del hecho constitutivo del derecho cuyo reconocimiento pretende; 2) cuando se trata ce la violación de un derecho, emanado de un acto contractual, deberá probar la existencia de éste; 3) cuando haya un hecho extintivo, impeditivo o modificativo en una obligación, deberá probar tal cosa; 4) si el demandado aduce un hecho que altere sustancialmente lo demandado, deberá probarlo. Por eso dá la siguiente noción. "Es de cargo de quien lo alegue, la prueba de la existencia del hecho en que se funde el derecho cuyo reconocimiento se pretende o que impida su constitución, modifique o extinga un derecho existente".

El diligenciamiento de una prueba consiste en el conjunto de actos procesales que es menester cumplir para trasladar al juicio los distintos elementos de convicción propuestos por las partes. En el procedimiento probatorio impera el principio de contradicción: toda prueba se produce con ingerencia y posible oposición de la parte a la que eventualmente puede perjudicar. Es tan importante este principio, gue su infracción acarrea. nulidad. La actuación de la pruebą tiene su término legal; los primeros días están dedicados al ofrecimiento y los demás a la actuación.

En cuanto a la valoración de la prueba, hay que tener en cuenta de lo que se trate, pues no todas ofrecen la misma certidumbre de veracidad. El procesalista uruguayo Profesor Couture establece el siguiente orJen en cuanto al valor de la prueba: 1) la prueba directa por percepción; es el contacto directo del juez con el objeto o hecho materia de la prue. ba, en la que no hay intermediario y cuya fidelidad es inobjetable. Fero también es la más difícil, pues los hechos que se controvierten en un juicio casi siempre son pasajeros y cuando interviene ol juez ya han desapareci. do, por lo que tiene que recurrirse a la sustitución; $2^{\circ}$ ) el medio sustitutivo de la percepción es la representación presente de un hecho ausente; puede ser mediante documentos o mediante el testimonio humano vertido por personas que directamente conocen el hecho; $3 \%$ ) faltando las anteriores, funciona la deducción del propio juez, que puede llegar a conocer hechos mediante deducciones lógicas; propiamente no es una prueba, sino un elemerto ${ }^{3}$ elaboración de la sentencia realizada por el juzgado.

El valor de la prueba es relativo. La inspección ocular es la prueba. 
por excelencia, salvo los incvitables errores humanos, pero también es la más rara, pues muy pocos casos pueden ser percibidos directamente por el juez. La representación más eficaz es la realizada mediante documento, hecho antes del juicio; aquí el intermediario queda reducido a ser espectador del valor del documento. Es la llamada prueba pre - constituída. Menos eficaz es la representación mediante el testimonio humano, pues tiene la gravísima falla del interés, ya que en la práctica cada parte declara conforme le conviene sin tener presente el juramento prestado. Cuando el testimonio es de un tercero, que no tiene interés en el litigio, existe el peligro del olvido y la confusión de ideas por el tiempo transcurrido.

Como regla general, existe la siguiente: "Existen variantes de eficacia entre los diversos medios de prueba, dependientes de la mayor o menor proximidad del juez con los motivos. A mayor proximidad, mayor grado de eficacia; a mayor lejanía, menor valor de convicción". (Couture, Ob. Cit. pág. 141).

Terminado el período probatorio, se pasa a alegar el derecho probado. Llámase Alegato de bien probado, el escrito en que las partes examinan la prueba presentada por ambas partes, con relación a los hechos afirmados en la demanda y contestación, procurando demostrar su exaccitud o inexactitud. Es una recapitulación hecha por los litigantes en forma metódica para facilitar al Juez su labor de sentenciador.

La última etapa en el desarrollo del proceso civil, es la Sentencia que ofrece al estudio diversos aspectos que veremos suscintamente.

Como hecho jurídico, la sentencia ofrece tres etapas: leer, pensar, escribir. Al tomar contacto con el proceso, el juez estudia, lee y examina, de allí la clásica fórmula de "Vistos". Luego examina meditando sobre los argumentos, extrayendo las consecuencias que de allí se derivan, serán ma* teria de los "Considerandos" que vienen a ser los raciocinios del Juez. Finalmente adquiere realidad el pensamiento del magistrado, escribiendo.

Como arto jurídico, la sentencia es una operación de carácter crítico; el juez elige entre las dos tesis de las partes, mediante un proceso intelectual. Antes se consideraba a la sentencia como un puro silogismo, que tenía sus premisas y la conclusión; la moderna ciencia procesal rechaza es" ta idea por estimar que en toda sentencia entran elementos no lógicos, y además el juez es un ser humano, sujeto a influencias de toda clase.

Como documento escrito, la sentencia sobrevive al juez; una vez en el papel no existirá otra voluntad que la allí escrita. El acto nace con anterioridad al documento, pero sobrevive merced a él.

La sentencia judicial es instrumento público; su destrucción no anula su eficacia, sino que exige su reconstrucción. Tiene pleno valor mientras no se pruebe la nulidad o falsedad en otro juicio. Es ley para las partes y lo que ella resuelve no puede ser materia de otra acción, salvo excepciones permitidas por la ley.

Las sentencias definitivas, o sean las dictadas para resolver el fondo del litigio, dan fin al proceso. Pueden ser: declarativas, de condena y constitutivas. Las primeras tienen por fin exclusivo declarar la existencia o inexistencia de un derecho. Las segundas imponen el cumplimiento de una prestación, bien sea de hacer o de no hacer. Las últimas crean, modifican o extinguen derechos, constituyendo un nuevo estado juridico para las partes. 
Efecto fundamental y principalísimo de la sentencia, es la producción de la cosa juzgada; lo resuelto es inamovible y tiene que ser aceptado por las partes. La retroactividad de la sentencia varía según su clase; es total en las declarativas; es parcial en las de condena, pues retrotraen los efectos desde el día en que se interpuso la demanda; no hay retroactividad alguna en las constitutivas, que se proyectan hacia el futuro únicamente.

Antes de alcanzar la condición inmutable de "cosa juzgada", la sentencia tiene que atravesar otros estadios, que enseguida veremos.

\section{III.-Eficacia del Proceso.}

El Juez puede incurrir en error en dos aspectos fundamentales: 1) apartándose de los medios señalados por el derecho procesal, privando a las partes de sus garantías y defenea, que es el "error in procedendo"; 2) aplicando un derecho inaplicable, no aplicando la ley o aplicándola mal es el "error in iudicando". El primer error afecta a! propio falio, a su validez procesal; el segundo no afecta a la ley, sino a la justicia. Ambos errores sólo pueden corregirse a pedido de parte, si no protesta quedan firmes, pues en materia procesal el consentimiento purifica las irregularidades.

Cuando el error puede ser corregido por el propio juez - caso de los decretos de mero trámite o error saltante- se pedirá Reposición. Pero cuando requiere la intervención del Superior, entonces existe la Apelación.

La apelación es el mejor medio de controlar la sentencia recurida. En Segunda Instancia no hay un nuevo juicio; salvo excepcinnes, sólo se limitan a examinar la sentencia recurrida, apreciando sus considerandos. Pucden apelar todos aquellos que, siendo partes en el proceso, han sufrido agravio con la parte resolutiva de la sentencia. Contra las resoluciones de? Tribuna! Superior, la ley franquea al litigante periudicado e! Recurso de Nulidad para otorgarle una garantía más ante la Corte Suprema, quien puede declarar la nulidad cuando se presenten errores in procedendo o in iu dicando; lo resuelto es inamovible, y pasa a la categoría de cosa juzgada. El proceso después de concluido, ha pasado por varios estadios con lo que se ofrece a los litigantes las máximas garantías de acierto en los fallos.

\section{IV.-Efectividad del Proceso.} manda.

Es la última etapa destinada a dar la satisfación pedida en la de.

La sentencia pasa a la categoría de Cosa Juzgada. Ia primera interrogante que se nos ofrece es sobre su naturaleza: ies de derecho natural o sólo de derecho positivo? Ambas teorías tienen sus partidarios, pero nos parece que participa de ambos caracteres. Es indispensable su existencia, pues de lo contrario la incertidumbre reinaría en ias relaciones sociales; la necesiclad de certeza indispensable a ella tierden los recursos que la ley concede. La ley la establece después de agotar todas las posibles vias de control, disminuyendo al mínimo las posibidades de un error iudicial. La ley establece la cosa juzgada y le fija sus límites alcanzando sólo a quienes han litigado. Sólo la parte dispositva de la sentencia constituye cosa juzgada, nunca la expositiva, salvo que e! juzgador se remita expresamente a los considerandos. 
La Ejecución de la sentencia está constituida por el conjunto de actos destinados a asegurar la eficacia de dicha sentencia que por hallarse en la situación de cosa juzgada, es indiscutible y coercible. La coerción permite invadir la esfera individual para dar satisfacción al vencedor. Varía el modo de ejecución segun la sentencia que sea: en las declarativas se reducirá a la publicidad del derecho declarado; en las constitutivas se asegurará el nuevo estado de derecho mediante la inscripción; y sólo en las de condena adquiere su fisonomía propia, asegurándose la ejecución mediante la coerción.

La coacción pertenece a la esencia del derecho, pues de lo contrario serían ilusorios. Funciona sobre las personas y sobre las cosas; el antiguo "arraigo" ha desaparecido del orden civil y penal, va que tampoco existe en el derecho moderno la prisión por deudas, hoy se grava el patrimonio de la persona. Sobre las cosas funciona de diversas maneras: actos de entrega material, en los que hay coacción física para extraer las cosas de manos del vencido y entregárselos al vencedor; obligaciones de hacer y de no hacer, en las primeras de las cuales el juez puede ordenar hacer la obra por cuenta del obligado, salvo que sea una obligación personalísima en cuyo caso sólo procede la indemnización, y en las segundas - de no hacer- también interviene un criterio económico con carácter indemnizatorio; finalmente tenemos la ejecución mediante la venta de bienes cuando se trata de pago de soles y ellos no están en el patrimonio del vencido; empieza con el embargo definitivo, o la conversión en tal si existiera como preventivo, y concluye con la venta pública en presencia del juez, quedando el saldo a beneficio del dueño, después de haber pagado la deuda y los gastos.

Nota: En nuestro próximo número publicaremos la segunda parte de éste artículo, que se refiere al Proceso Penal. 